\title{
Особенности ценностно-мотивационной сферы личности психологов и психиатров
}

\author{
Елена А. Кедярова', Маргарита Ю. Уварова', Надежда И. Чернецкая", \\ Ольга А. Шумовская \\ 1 Иркутский государственный университет, г. Иркутск, Российская Федерация \\ 2 ОГАУЗ ИГКБ № 1, г. Иркутск, Российская Федерация \\ *E-mail: cherna@yandex.ru
}

\begin{abstract}
Аннотация
Ввеление. Целью исследования было изучение особенностей ценностно-мотивационной сореры личности психологов и психиатров на этапе профрессиональной самореализации. Большинство предпринятых в послеАние Аесятилетия исслеАОваний на эту тему сфокусированы больше на фрормировании психологической готовности к труАОвой Аеятельности при получении профрессионального образования и при вхожАении в профеессиональную Аеятельность. Аальнейшие этапы профрессионализации врачей и психологов чаще всего изучаются в контексте проблемы профессионального выгорания. Новизна Аанного исследования закАючается в сравнительном изучении особенности ценностно-мотивационной сфреры ^ичности психологов и психиатров, специфика Аеятельности которых характеризуется повышенной стрессогенностью и эмоциональной напряженностью. Методы. Были использованы психодиагностические тестовые метоАики: «Аиагностика мотивационной структуры ^ичности», «Направ^енность ^ичности», «Когнитивная ориентация», «МАС», «Мотивация афорилиации», «Мотивация труАовой Аеятельности», «Ценностные ориентации», «Оценка удовлетворенности потребностей методом парных сравнений», «Степень напряженности», а также угловое преобразование Фишера Аля проверки статистической Аостоверности различий межАу сравниваемыми группами.
\end{abstract}

Результаты. Проведенное исследование показало, что Аля ценностно-мотивационной сореры мичности психиатров и психологов характерен ряА различий. Мотивационная направленность мичности психиатров в большей степени связана с социальным статусом и жизнеобеспечением, в отличие от психологов, А^я которых более важными являются общая активность и социальная полезность. Кроме того, А^я психологов характерным яв^яется высокий уровень когнитивных потребностей, А^я психиатров же более важными являются потребности в самореализации и социальные потребности. Аанные результаты соотносятся с особенностями ценностных ориентаций: А^я психологов более важной является инструментальная ценность - «образованносты), А^я психиатров - «терпимость». 
пСИхолОГИЯ ТРУДА

ОбсужАение результатов. Аелается вывоА О выявленных различиях в ценностно-мотивационной сорере психиатров и психологов. Предполагается, что некоторые из них, в процессе профрессиональной самореализации, могут служить основанием Аля формирования успешной профессиональной Аеятельности, а Аругие, наоборот, возникновению синАрома эмоционального выгорания.

\title{
КАючевые слова
}

мотивация, ценностные ориентации, мотивационная направленность, ценностно-мотивационная сорера, профрессиональная Аеятельность, психиатр, психолог, психология профрессионализации, психология профрессий, психология врача

\section{Основные положения}

- особенности ценностно-мотивационной сфееры личности специалистов в периол профессиональной самореализации могут способствовать успешной профрессиональной Аеятельности, а Аругие, наоборот, возникновению синАрома эмоционального выгорания;

- уАовлетворенность профрессиональной самореализацией взаимосвязана с конструктивной профрессиональной мотивацией и проявляется в большей степени у психологов;

- неконструктивная профрессиональная мотивационная направленность, неуАовлетворенность в самореализации в большей степени характерны Аля психиатров - слеАовательно, у Аанной группы специалистов может быть выше риск возникновения синАрома профрессионального выгорания.

\section{Для цитирования}

Кедярова Е. А., Уварова М. Ю., Чернецкая Н. И., Шумовская О. А. Особенности ценностно-мотивационной сферы личности психологов и психиатров // Российский психологический журнал. 2019. T. 16, № 1. C. 77-102. DOI: 10.21702/rpj.2019.1.4

Материалы статьи получены 22.05.2018

\section{Characteristics of Personal Value Motivational Sphere in Psychologists and Psychiatrists}

\author{
Elena A. Kedyarova', Margarita Yu. Uvarova', Nadezhda I. Chernetskaya1*, \\ Ol'ga A. Shumovskaya ${ }^{2}$ \\ ${ }^{1}$ Irkutsk State University, Irkutsk, Russian Federation \\ ${ }^{2}$ Irkutsk City Clinical Hospital no.1, Irkutsk, Russian Federation \\ *Corresponding author. E-mail: cherna@yandex.ru
}




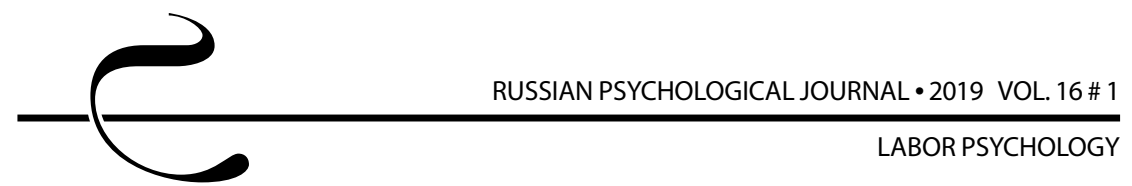

\section{Abstract}

Introduction. This study investigates the characteristics of personal value motivational sphere in psychologists and psychiatrists at the stage of professional self-realization. Previous studies in this field have mainly been focused on studying the formation of psychological readiness for work at the stage of professional training or when entering into professional activity. Further stages of the professionalization of physicians and psychologists are most often considered in the context of professional burnout. The presence of stressful situations and emotional tension are characteristic of professional activities of psychologists and psychiatrists. This study compares the characteristics of value motivational sphere in these professional groups.

Methods. The study used the following techniques: (a) Diagnostics of Personal Motivational Structure, (b) Personality Orientation, (c) Cognitive Orientation, (d) MAS, (e) Motivation of Affiliation, (f) Motivation of Labor Activity, (g) Value Orientations, (h) Assessment of Satisfaction of Needs by the Method of Paired Comparisons, and (i) Degree of Tension. The differences between the two groups were assessed using Fisher's angular transformation.

Results. This study revealed certain differences in personal value motivational sphere in psychiatrists and psychologists. In the group of psychiatrists personal motivational orientation is more related to social status and livelihood. General activity and social utility are most important characteristics in the group of psychologists. Besides, psychologists are characterized by a high level of cognitive needs; needs for selfrealization and social needs are more important for psychiatrists. The findings of the study correlate well with the characteristics of value orientations. Thus, the instrumental value of 'education' is more important for psychologists; the value of 'tolerance' is more important for psychiatrists.

Discussion. The authors suggest that in the process of professional self-realization certain characteristics of value motivational sphere in psychiatrists and psychologists may contribute to the formation of their successful professional activity. On the contrary, there are characteristics of value motivational sphere that may lead to emotional burnout.

\section{Keywords}

motivation, value orientations, motivational orientation, value motivational sphere, professional activity, psychiatrist, psychologist, psychology of professionalization, psychology of professions, psychology of physicians

\section{Highlights}

- In the process of professional self-realization certain characteristics of value motivational sphere in specialists may contribute to the formation of their successful professional activity. On the contrary, there are characteristics of value motivational sphere that may lead to emotional burnout. 
Satisfaction with professional self-realization is associated with constructive professional motivation and manifests itself mainly in the group of psychologists.

- Non-constructive professional motivational orientation and dissatisfaction with selfrealization are more typical of psychiatrists. Therefore, the risk of developing professional burnout seems to be higher in this professional group.

\section{For citation}

Kedyarova E. A., Uvarova M. Yu., Chernetskaya N. I., Shumovskaya O. A. Characteristics of Personal Value Motivational Sphere in Psychologists and Psychiatrists. Rossiiskii psikhologicheskii zhurnal - Russian Psychological Journal, 2019, V. 16, no. 1, pp. 77-102 (in Russian). DOI: 10.21702/rpj.2019.1.4

Original manuscript received 22.05.2018

\section{Введение}

Современные тенденции развития рынка труда предъявляют особенно высокие требования к личности специалистов помогающих профессий (врачей, педагогов, психологов, социальных работников и проч.), и просто качественной образовательной подготовки в их случае больше не достаточно: именно эти специалисты более остальных «работают душой», включаются в свою деятельность всей своей личностью, а не просто реализуют полученные знания, умения и навыки. Весь комплекс личностных качеств, являющихся наряду со знаниями, умениями и навыками инструментом профессиональной деятельности таких специалистов, называют то просто «ПВКЛ» (профессионально важные качества личности), то в русле современных терминологических тенденций - профессиональной психологической компетентностью $[1,2,3]$.

При этом уделяется особое внимание психологической подготовке данных специалистов, ведь совершенно ясно, что именно на этапе получения профессионального образования должна закладываться не только система непосредственных инструментальных компетенций, но и система мотивов и ценностей профессионала, помогающего людям [4, 5, 6, 7].

В обозначенном контексте ценностно-мотивационная сфера личности профессионала (в нашем случае это врачи-психиатры и психологи) в системе профессиональной психологической компетентности приобретает особое место: именно эта сфера является системообразующим звеном личности, задает направление всей трудовой деятельности, определяет ее личный стиль. По мнению ряда авторов (М. И. Дьяченко, В. Ф. Жуковой, Л. А. Кандыбович, И. А. Кучерявенко, В. Д. Шадрикова и др.), ценности и мотивы профессионала являются определяющими в его самореализации $[8,9,10,11,12]$. 
Л. М. Емельяненко дополнительно уточняет, что ценностно-мотивационная сфера личности профессионала-врача, профессионала-педагога или профессионала-психолога выступает интегральным психическим образованием, делающим все профессиональные действия не механической работой, а осмысленной деятельностью. Ценности и мотивы личности формируют устойчивые профессиональные установки и профессиональную направленность, отражающие не только профессиональный, но и морально-нравственный уровень человека в труде [13].

Имеется ряд публикаций (А. Т. Араслановой, О. И. Комолкиной, А. Н. Нугаевой, S. Budhathoki, P. Heiligers, R. Kusurkar и др.), раскрывающих особенности различных аспектов ценностно-мотивационной сферы личности специалистов помогающих профессий на этапе профессионального образования: студентов медицинских вузов $[14,15,16,17,18]$, учащихся медицинских колледжей [19, $20,21]$, студентов-психологов [22].

А. А. Фитьмовой выявлено, что будущие врачи непозволительно часто демонстрируют неконструктивную профессиональную мотивацию (ориентированы на карьеру или на интеллектуальное превосходство с низким интересом к содержанию самой врачебной деятельности), что негативно сказывается на усвоении учебной программы, проявляется в невнимании к мелочам и деталям [14]. В. М. Зайцева показала, что только около трети будущих врачей имеют выраженный альтруистический профессиональный мотив помощи людям [15].

Преобладающая мотивационная направленность на общежитейский уровень взаимосвязана с более высоким риском возникновения синдрома эмоционального выгорания [23, 24]. При этом P. Heiligers установил, что конструктивная мотивационная направленность характернее для будущих врачей мужского пола, а выгорание у таких врачей-мужчин наступает позже [17].

А. Н. Нугаева отмечает, что уровень гуманистических и альтруистических ценностей будущих психологов практически не меняется в ходе обучения, несмотря на кажущуюся очевидность предположения, будто психологическое образование непременно формирует гуманистически направленную личность. Автор называет эту желательную для психологов ценностно-мотивационную направленность нравственно-деловой и подчеркивает, что она, к сожалению, не формируется автоматически в ходе образовательной подготовки [22].

Таким образом, большинство предпринятых в последнее время исследований ценностно-мотивационной сферы личности медицинских работников и психологов касаются начальных этапов профессионализации и выполнены в контексте проблемы психологической готовности к профессиональной деятельности. При этом изучение особенностей ценностей и мотивации уже работающих врачей и психологов очень важно с учетом необходимости их 
психологического сопровождения, сохранения их психологического здоровья $[25,26,27,28]$.

Актуальность сравнительного исследования ценностно-мотивационной сферы личности психологов и психиатров обусловлена, как минимум, двумя причинами.

Во-первых, профессиональная деятельность в области психологии и психиатрии относится к числу наиболее стрессогенных, наиболее истощающих психические ресурсы самих специалистов. Значимыми составляющими профессионального успеха психологов и психиатров являются любовь к людям, выраженная рефлексивность, эмпатичность, но именно названные качества относятся к наиболее «истощающим», наиболее «предрасполагающим» к эмоциональному выгоранию [29].

Во-вторых, сама суть психологии и психиатрии различна: если психолог по содержанию своей деятельности направлен на взаимодействие и развитие, то психиатр - на болезнь и ее лечение, что делает ценностно-мотивационные сферы личности специалистов, выбравших тот или иной путь помощи людям, изначально различными [30]. Впрочем, некоторые авторы, например, L. Eisenberg, указывают на то, что современная психиатрия непрерывно движется по пути гуманизации [31]. В целом же мы считаем правомерным предполагать, что психологи и психиатры уже на этапе получения профессии имеют разные ценностные и мотивационные качества, что делает сравнительное исследование этих качеств актуальным для сопровождения их профессиональной деятельности на всех этапах профессионализации.

\section{Методы}

Эмпирическое исследование проводилось на базе Медико-психологического центра, отделения пограничных состояний, наркологического отделения Ангарской областной психиатрической больницы, а также пяти кризисных психологических консультационных центров г. Ангарска, г. Иркутска и г. Братска (муниципальных и частных) в 2006-2015 гг. (частью данного исследования является дипломная работа И. Ю. Тарасовой, выполненная в 2006 г. в Иркутском государственном университете. -Прим. aвт.).

Первую выборку исследования составили 50 психологов. Вторую выборку составили 50 психиатров. Исследуемый контингент специалистов составляют женщины (70\% в выборке психологов и 60 \% в выборке психиатров) и мужчины (соответственно, 30 \% в выборке психологов и 40 \% в выборке психиатров) в возрасте от 25 до 45 лет. Распределение по возрасту в сравниваемых выборках было одинаковым, т. е. средний возраст и размахи по возрасту в них были приблизительно равными. Распределение по полу немного различается в двух выборках, но не настолько, чтобы это различие могло лечь в основу 
конкурирующей гипотезы, поэтому в дальнейшей работе данное различие в распределении мы будем игнорировать.

Был использован психодиагностический комплекс, включавший в себя следующие методики: «Диагностика мотивационной структуры личности» (В. Э. Мильман), «Направленность личности» (В. Смейкал и М. Кучер), «Когнитивная ориентация (локус контроля)» (Дж. Роттер), «МАС» М. Кубышкиной, «Мотивация аффилиации» А. Меграбяна в модификации М. Ш. Магомед-Эминова, «Мотивация трудовой деятельности», «Ценностные ориентации» М. Рокича, «Оценка удовлетворенности потребностей методом парных сравнений» (В. В. Скворцов), «Степень напряженности» [32, 33, 34].

\section{Результаты}

На рисунке 1 показаны усредненные значения общей и творческой активности, стремления к общению, обеспечению комфорта и социального статуса.

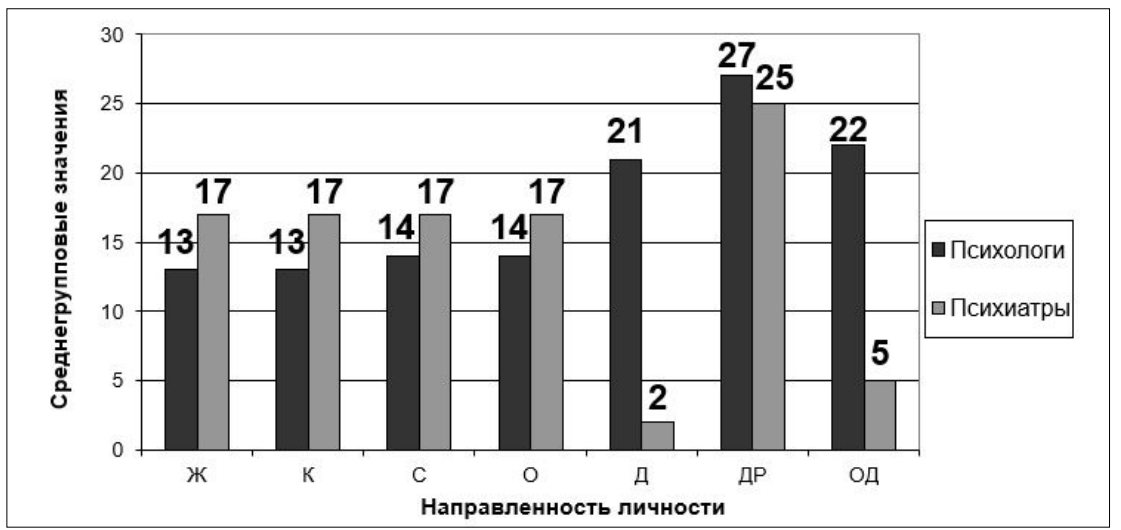

Рисунок 1. Соотношение усредненных показателей мотивационной структуры Аичности психологов и психиатров

Условные обозначения:Ж-жизнеобеспечение; К-комфорт; C- сочиальный статус; О-общение; Д-общая активность; ДР-творческая активность; ОД-сочиальная полезность.

Figure 1. Correlations among mean values of personal motivational structure in the groups of psychologists and psychiatrists

Legend: K-livelihood (L); $K$-comfort (C); C - social status (S); $O$-communication (C); $\mathrm{A}$ - general activity (G); $Д P$ - creative activity (CA); ОД-social utility (SU).

Как видно из рисунка 1, между направленностью личности психологов и психиатров выявлены различия. В группе психиатров выявлено доминирование стремления к упрочнению социального статуса, к общению, 
к обеспечению комфорта и жизнеобеспечения. У представителей группы психологов доминируют общая активность и социальная полезность. Но самое высокое значение показателей направленности в мотивационной структуре личности, как у психологов, так и у психиатров, занимает параметр «творческая активность».

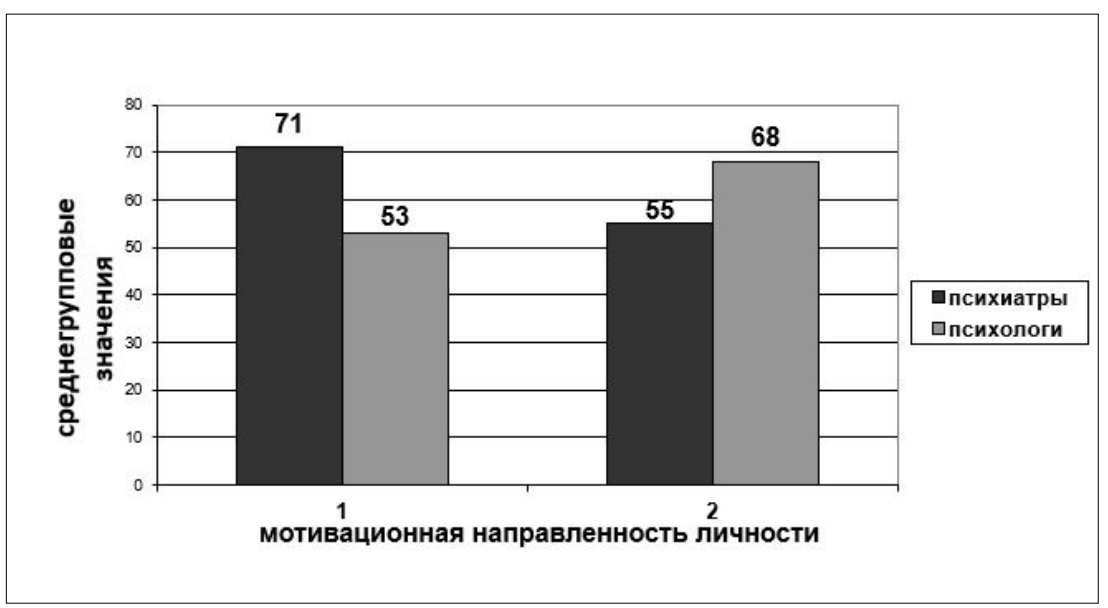

Рисунок 2. Соотношение показателей рабочей и общежитейской мотивационной направленности в группах психологов и психиатров

Условные обозначения: 1 - рабочая мотивационная направленность; 2-общежитейская мотивачионная направленность.

Figure 2. Correlations between the values of working and general life's motivational orientation in the groups of psychologists and psychiatrists

Legend: 1 - working motivational orientation; 2 -general life's motivational orientation.

По рисунку 2 можно также наблюдать различия в мотивационной направленности в группах психологов и психиатров, где в первом случае («рабочая» направленность) показатель равен 71, что превышает показатель психиатров, равный 53. Во втором случае рассматривается общежитейская направленность личности, где тоже видны различия между психологами и психиатрами: у психиатров показатель равен 68 , а у психологов - 55 , что показывает общежитейскую направленность психиатров.

Выраженная рабочая направленность психологов, вероятно, свидетельствует о том, что они заинтересованы в решении деловых проблем, ориентированы на деловое сотрудничество, способны отстаивать в интересах дела собственное мнение, которое полезно для достижения общей цели. Выраженная 
общежитейская направленность психиатров, вероятно, свидетельствует о том, что они стремятся при любых условиях поддерживать отношения с людьми, ориентированы на социальное одобрение. Можно также предполагать, что наличие в выборке психологов специалистов, работающих в полностью коммерческих консультационных центрах, смещает направленность психологов в сторону деловой, в то время как психиатры, работающие в муниципальных медицинских учреждениях, более безразличны к своей работе.

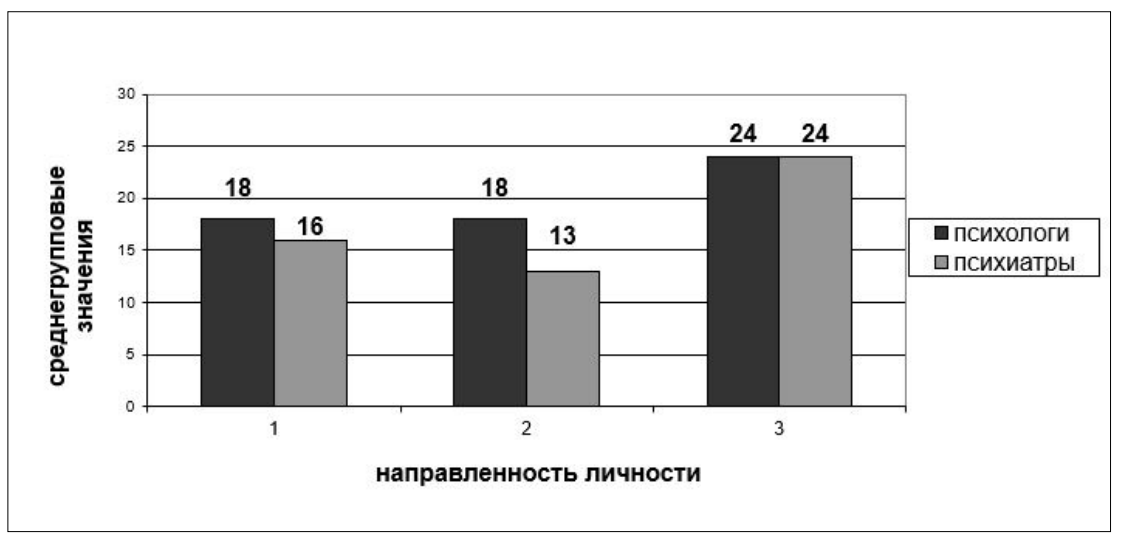

Рисунок 3. Соотношение показателей виАов направленности ^ичности представителей обеих групп испытуемых

Условные обозначения: 1 - направленность на себя; 2- на взаимоотношения; 3-на задание.

Figure 3. Correlations among the values of types of personal orientation in the groups of psychologists and psychiatrists

Legend: 1 - orientation towards self; 2 -orientation towards relationship; 3 - orientation towards work.

Из рисунка 3 видно, что у психологов и психиатров в равной степени обнаружены высокие показатели направленности личности на задание - это отражает интенсивность, с которой исследуемые специалисты выполняют задание, решают проблемы, и в какой мере они заинтересованы выполнять свою работу как можно лучше. Если сравнить среднегрупповые показатели направленности на себя и на взаимодействие, то у психологов они выше. Это, вероятно, говорит о том, что психологи ожидают прямого вознаграждения и удовлетворения независимо от того, какую работу и с кем они выполняют.

Как видно из представленного рисунка 4, у психологов и психиатров среднегрупповые показатели интернальности ярко выражены. Но, тем не менее, у психиатров интернальность чуть выше. Это, вероятно, говорит о том, что психиатры более убеждены, что их успехи или неудачи не случайны 
и зависят от собственной компетентности, способностей, целеустремленности. Предполагается, что их интересы направлены на внутренний мир человека, который более значим, чем мир предметов и внешних обстоятельств. Вероятно, психиатры предпочитают индивидуальную работу. Экстернальность психологов обусловлена, вероятно, их социальной открытостью, гибкостью поведения.

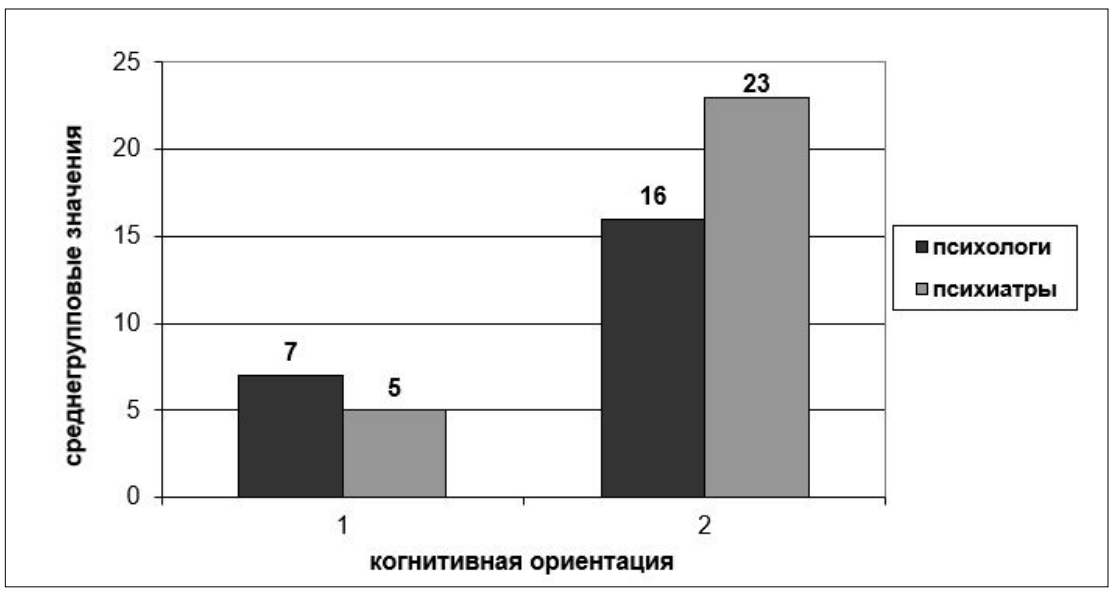

Рисунок 4. Соотношение показателей когнитивной ориентации групп психологов и психиатров

Условные обозначения: 1 - экстерналъность; 2-интернальность.

Figure 4. Correlations between the values of cognitive orientation in the groups of psychologists and psychiatrists

Legend: 1 -externality; 2 -internality.

Рассмотрев рисунок 5, можно также увидеть различия и по показателям мотивации психологов и психиатров. У психиатров преобладает стремление к социальному престижу, а у психологов преобладает стремление к соперничеству, их среднегрупповые значения равны 18. Стремление к достижению цели, по данным среднегрупповых значений, у исследуемых специалистов слабо выражено, среднегрупповые показатели по данному параметру равны 11. Выраженное стремление к соперничеству у психологов формирует привычку сравнивать свои наличные достижения с достижениями других; предполагается, что это связано с возрастающими требованиями к уровню мастерства специалистов, наличием конкурентов, готовностью специалистов к профессиональному и личностному самоутверждению. Преобладающее у психиатров стремление к социальному престижу выражается в желании 
специалистов повышать свою значимость как профессионалов, развивать свои навыки и умения, ценить себя.

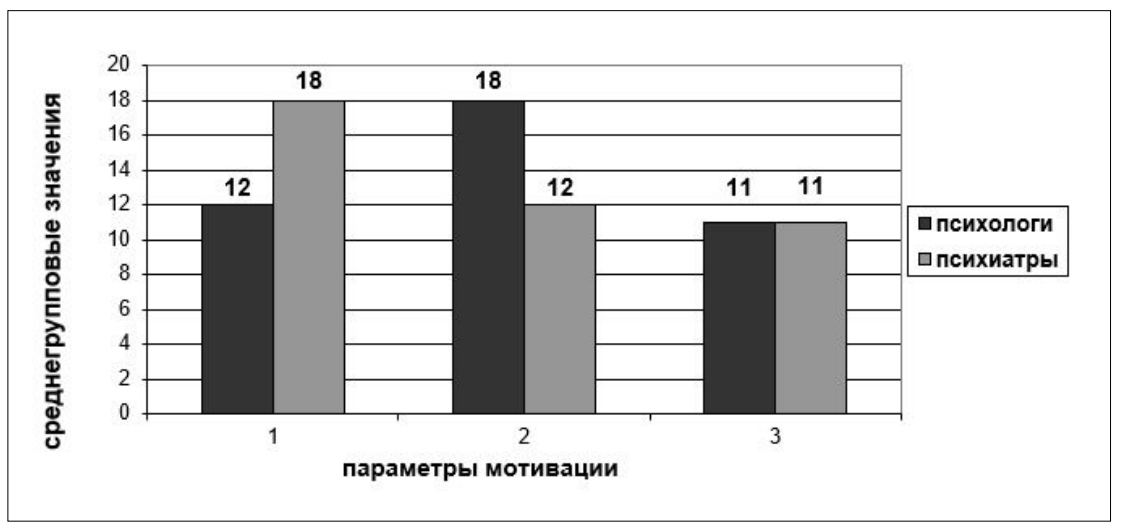

Рисунок 5. Соотношение показателей мотивации психологов и психиатров

Условные обозначения: 1 -стремление к сочиальному престижу; 2-стремление к соперничеству; 3-стремление к достижению цели.

Figure 5. Correlations among the values of motivation in the groups of psychologists and psychiatrists

Legend: 1 - motivation towards social prestige; 2 -motivation towards competition; 3 - motivation towards goal achievement.

Из рисунка 6 видно, что полученные среднегрупповые значения близки к среднему уровню развития мотива. Тем не менее, у психологов по первому показателю (мотив «стремление к людям») среднегрупповое значение равно 162, что превышает показатель среднегруппового значения данного мотива у психиатров. У них выявлены средние значения мотивационных тенденций «стремление к людям» и «боязнь быть отвергнутым». Специалисты, обладающие такими мотивами, не рассматривают окружающих как средство удовлетворения личных потребностей, не стремятся к доминированию над ними, а рассчитывают на сотрудничество.

Можно отметить, что у психологов наиболее благоприятно сочетание обоих мотивационных стремлений, при котором «стремление к людям» развито сильно, а «боязнь быть отвергнутым» - средне. Доминирование у человека мотива «стремление к людям» порождает стиль общения с людьми, характеризующийся уверенностью, непринужденностью, открытостью и смелостью. Внешне это проявляется в особой озабоченности человека установлением, поддержанием дружеских взаимоотношений с людьми. 


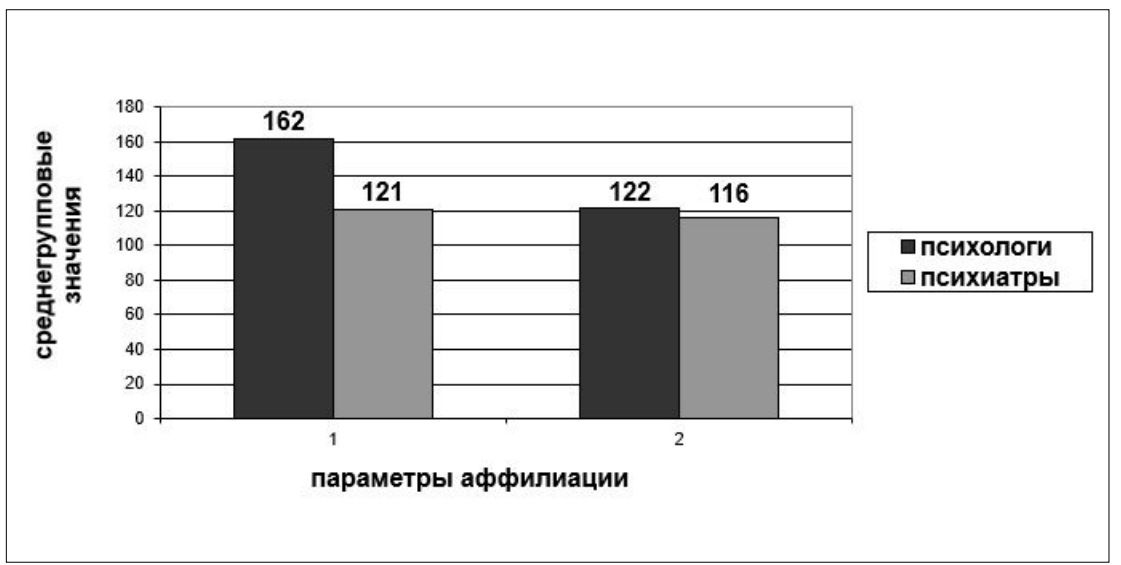

Рисунок 6. Соотношение показателей афффилиации у психологов и психиатров

Условные обозначения: 1 - оченка стремления к людям; 2 - оценка боязни быть отвергнутым.

Figure 6. Correlations between the values of affiliation in the groups of psychologists and psychiatrists

Legend: 1 - orientation towards people; 2 -fear of rejection.

Данный мотив коррелирует со стремлением человека к одобрению со стороны окружающих людей, с уверенностью и желанием самоутверждения, проявлением большой активности и инициативы в общении с окружающими. Специалисты с преобладанием данного мотива достигают более высоких результатов в работе в тех случаях, когда они трудятся не в одиночку, а в составе группы. У них, как правило, более высокий уровень социальной активности, проявляющийся в стремлении включаться в соревнование, организовывать работу других людей.

Из рисунка 7 видно, что у психологов наибольшее среднегрупповое значение по количеству баллов получила когнитивная потребность, а у психиатров - потребность в самореализации. Возможно, у психологов трудовое поведение больше направлено на приобретение новых знаний, получение новой информации, изучение новых методов и т. д. Психиатры же склонны к реализации своего потенциала и роста как личности.

На втором месте у психологов выступает потребность в самореализации, а у психиатров - социальные (межличностные) потребности. На третьем месте по уровню значимости для психологов и психиатров являются физиологические потребности (отдых, жилье, питание) в равной степени значимости. На четвертом месте у психологов - социальные потребности, 
у психиатров - когнитивные. На пятом месте - одинаково значимой для психологов и психиатров оказалась потребность в безопасности.

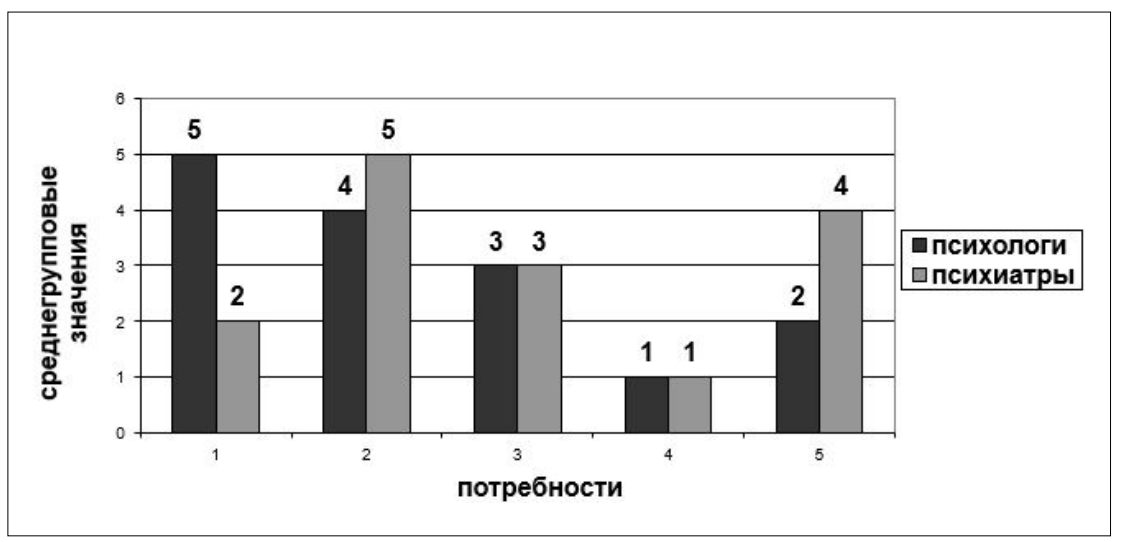

Рисунок 7. Соотношение показателей мотивации трудового поведения у психологов и психиатров

Условные обозначения: 1 - когнитивные потребности; 2-потребности самореализации; 3 физиологические потребности; 4-потребности в безопасности; 5-социальные потребности.

Figure 7. Correlations among the values of motivation towards labor behavior in the groups of psychologists and psychiatrists

Legend: 1-cognitive needs; 2 -self-realization needs; 3 - physiological needs; 4-safety needs; 5 -social needs.

Потребности, занимающие первое место у психологов и психиатров, можно отнести к потребностям роста (к высшим потребностям), а достичь высшую ступень пирамиды мотивов можно, только удовлетворив потребности низшего уровня. Зная свои основные мотивы, специалисты могут научиться контролировать их, для того чтобы развивать свою волю, а с этого и начинается подлинное развитие личности профессионала. Большое значение имеет то, что, «оттолкнувшись» от низших мотивов, человек «перерастает» самого себя и начинает решать принципиально иные задачи, связанные с подлинным смыслом учения - задачи развития своих способностей (для того чтобы понять свое предназначение).

Рассмотрев рисунок 8, можно увидеть различия между терминальными ценностями психологов и психиатров. Самую высокую оценку в баллах по результатам среднегрупповых значений у психиатров получили ценности познания (возможность расширения своего образования, кругозора, общей культуры, интеллектуального развития), а у психологов первое место по значимости занимают ценности здоровья (психического и физического). 


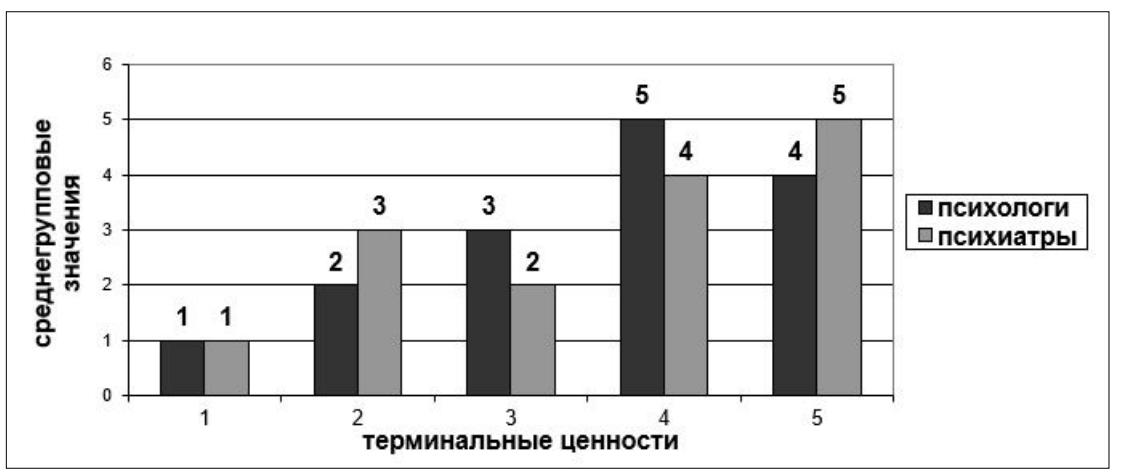

Рисунок 8. Соотношение показателей терминальных ценностей у психологов и психиатров

Условные обозначения: 1 -уверенность в себе; 2-счастливая семейная жизнь; 3-интересная работа; 4-здоровье; 5-познание.

Figure 8. Correlations among the values of ultimate values in the groups of psychologists and psychiatrists

Legend: 1 -self-confidence; 2 - happy family life; 3-interesting work; 4-health; 5-knowledge.

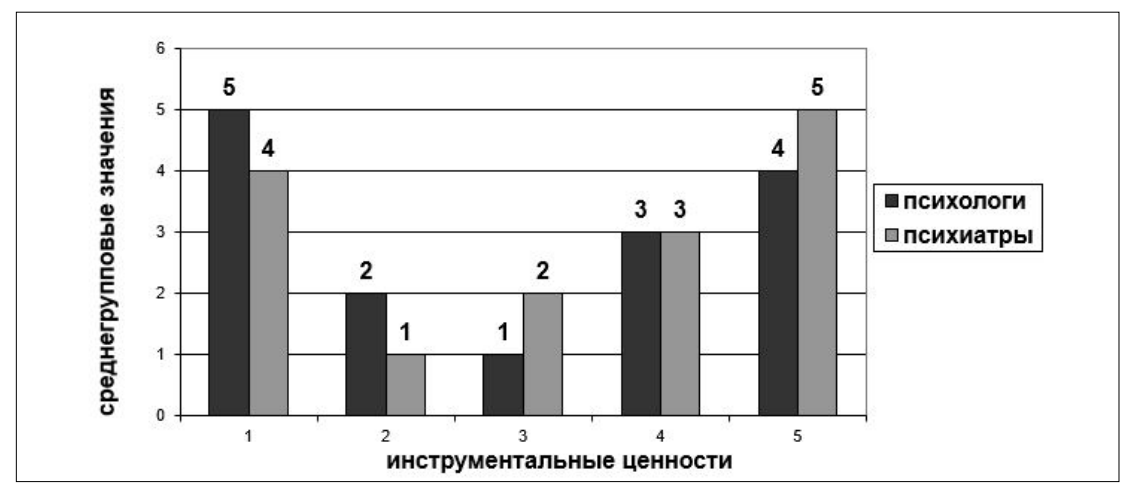

Рисунок 9. Соотношение показателей инструментальных ценностей у психологов и психиатров

Условные обозначения: 1 - образованность; 2-жизнерадостность; 3 - честность; 4- широта взглядов; 5-терпимость.

Figure 9. Correlations among the values of instrumental values in the groups of psychologists and psychiatrists

Legend: 1 -education; 2 - vitality; 3-honesty; 4-breadth of views; 5 -tolerance. 
Из рисунка 9 видны различия между инструментальными ценностями психологов и психиатров. Для психологов наиболее значимой инструментальной ценностью является образованность (широта знаний, высокая общая культура), т. к. среднегрупповой показатель равен 5 баллам. У психиатров первое место по значимости занимает инструментальная ценность - терпимость (к взглядам и мнениям других, умение прощать другим их ошибки и заблуждения).

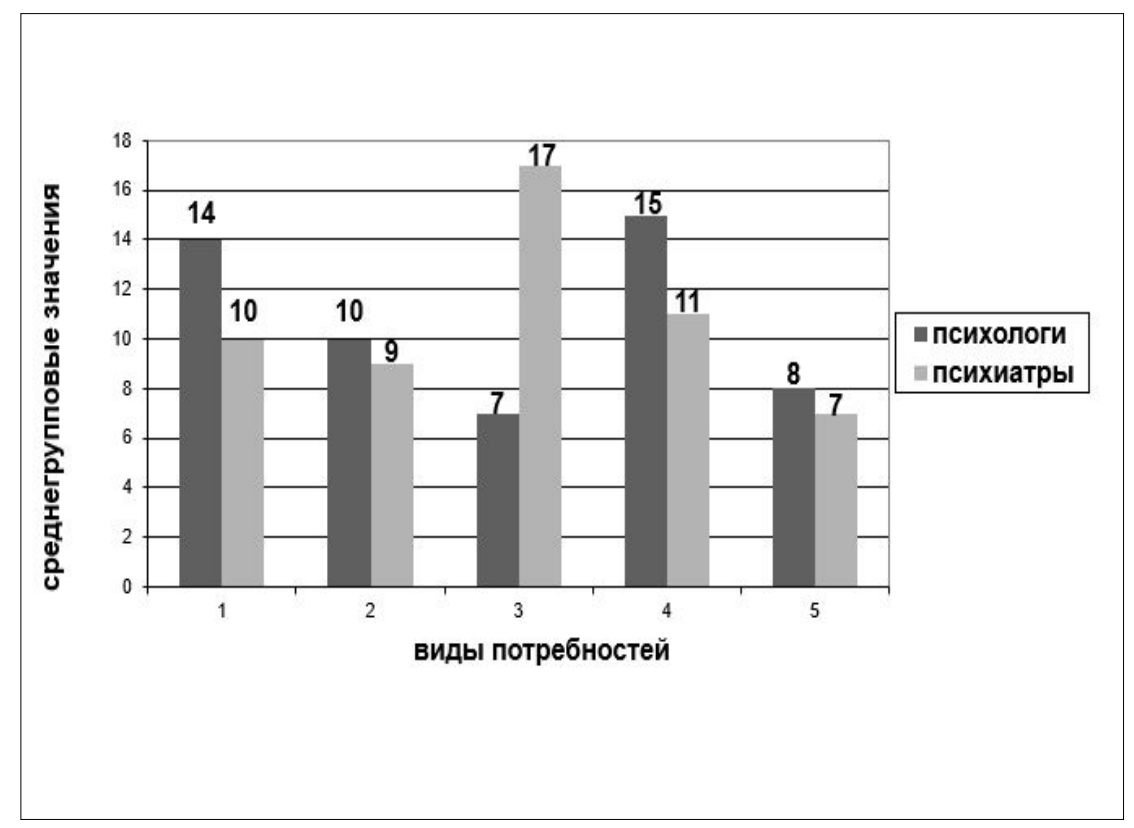

Рисунок 10. Соотношение показателей удовлетворенности пяти главных потребностей у психологов и психиатров

Условные обозначения: 1-материальные потребности; 2-потребности в безопасности; 3-потребности в самовыражении; 4-потребности в признании; 5-соииальные (межличностные) потребности. Figure 10. Correlations among the values of five basic needs satisfaction in the groups of psychologists and psychiatrists

Legend: 1 - material needs; 2 - safety needs; 3 - self-expression needs; 4 - recognition needs; 5 -social (interpersonal) needs.

На рисунке 10 видны различия по степени удовлетворенности потребностей у психологов и психиатров. У психологов на границе зон частичной неудовлетворенности и удовлетворенности находятся материальные потребности, 
а также потребности в признании. У психиатров в зоне частичной неудовлетворенности находятся потребности в самовыражении. Остальные потребности психологов и психиатров находятся в зоне удовлетворенности.

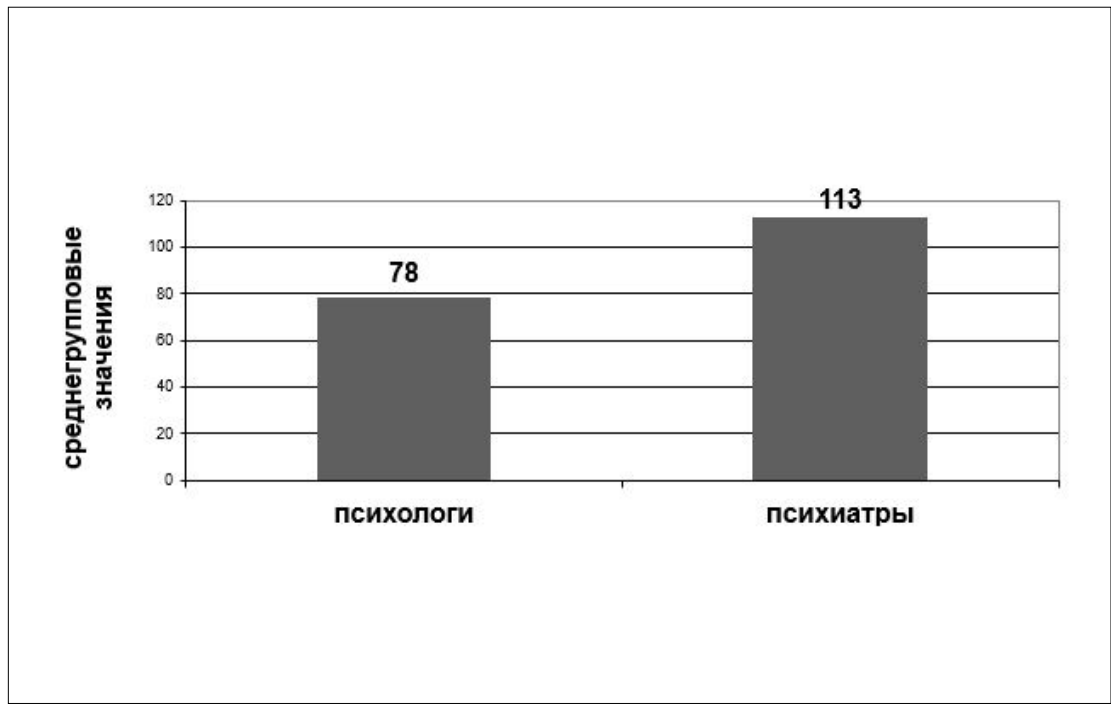

Рисунок 11. Соотношение показателей психической напряженности у психологов и психиатров

Figure 11. Correlations among the values of mental tension in the groups of psychologists and psychiatrists

Из рисунка 11 видно, что психологи достоверно отличаются от психиатров по уровню психической напряженности, вызванной несоответствием личностных притязаний реальному их удовлетворению. У психологов показатель психической напряженности соответствует удовлетворительному психическому состоянию, тогда как у психиатров показатель психической напряженности соответствует повышенной дискомфортности. У них преобладает повышенная дискомфортность, что связано с принятием большой ответственности на себя за состояние пациента.

Различия между сравниваемыми группами были проверены статистически (см. таблицу 1). 
Таблица 1. Эмпирические значения Ф-углового преобразования Фишера

Table 1. Empirical values of the Fisher's angular transformation ( $\varphi$-test)

\begin{tabular}{|c|c|c|c|}
\hline № & $\begin{array}{l}\text { Эмпирические тестовые параметры } \\
\text { мотивационной сфреры } \\
\text { Empirical values of motivational sphere }\end{array}$ & $\begin{array}{l}\varphi_{\text {эмп. }} \\
\varphi_{\text {emp. }}\end{array}$ & $\begin{array}{l}\text { Значимость } \\
\text { Significance }\end{array}$ \\
\hline \multicolumn{4}{|c|}{$\begin{array}{c}\text { Показатели мотивационной структуры мичности } \\
\text { Values of personal motivational structure }\end{array}$} \\
\hline 1 & $\begin{array}{l}\text { Жизнеобеспечение } \\
\text { Livelihood }\end{array}$ & 1,06 & \\
\hline 2 & $\begin{array}{l}\text { Комсрорт } \\
\text { Comfort }\end{array}$ & 1,17 & \\
\hline 3 & $\begin{array}{l}\text { Социальный статус } \\
\text { Social status }\end{array}$ & 1,38 & \\
\hline 4 & $\begin{array}{l}\text { Общение } \\
\text { Communication }\end{array}$ & 1,98 & $p<0,05$ \\
\hline 5 & $\begin{array}{l}\text { Общая активность } \\
\text { General activity }\end{array}$ & 0,87 & \\
\hline 6 & $\begin{array}{l}\text { Творческая активность } \\
\text { Creative activity }\end{array}$ & 2,87 & $p<0,01$ \\
\hline 7 & $\begin{array}{l}\text { Социальная полезность } \\
\text { Social utility }\end{array}$ & 0,26 & \\
\hline \multicolumn{4}{|c|}{$\begin{array}{l}\text { Показатели общей мотивационной направленности } \\
\text { Values of general motivational orientation }\end{array}$} \\
\hline 8 & $\begin{array}{l}\text { Рабочая мотивационная } \\
\text { направленность } \\
\text { Working motivational orientation }\end{array}$ & 2,16 & $p<0,05$ \\
\hline 9 & $\begin{array}{l}\text { Общежитейская мотивационная } \\
\text { направленность } \\
\text { General life's motivational orientation }\end{array}$ & 0,98 & \\
\hline \multicolumn{4}{|c|}{$\begin{array}{l}\text { Показатели профрессиональной мотивационной направленности } \\
\text { Values of professional motivational orientation }\end{array}$} \\
\hline 10 & $\begin{array}{l}\text { Направленность на себя } \\
\text { Orientation towards self }\end{array}$ & 0,77 & \\
\hline 11 & $\begin{array}{l}\text { Направленность на взаимоотношения } \\
\text { Orientation towards relationship }\end{array}$ & 3,18 & $p<0,01$ \\
\hline 12 & $\begin{array}{l}\text { Направленность на залание } \\
\text { Orientation towards work }\end{array}$ & 1,56 & \\
\hline
\end{tabular}




\begin{tabular}{|c|c|c|c|}
\hline № & $\begin{array}{l}\text { Эмпирические тестовые параметры } \\
\text { мотивационной сферы } \\
\text { Empirical values of motivational sphere }\end{array}$ & $\begin{array}{l}\varphi_{\text {эмп. }} \\
\varphi_{\text {emp }}\end{array}$ & $\begin{array}{l}\text { Значимость } \\
\text { Significance }\end{array}$ \\
\hline \multicolumn{4}{|c|}{$\begin{array}{c}\text { Когнитивная мотивационная ориентация } \\
\text { Cognitive motivational orientation }\end{array}$} \\
\hline 13 & $\begin{array}{l}\text { Экстернальность } \\
\text { Externality }\end{array}$ & 1,47 & \\
\hline 14 & $\begin{array}{l}\text { Интернальность } \\
\text { Internality }\end{array}$ & 1,52 & \\
\hline \multicolumn{4}{|c|}{$\begin{array}{l}\text { Социальные мотивы } \\
\text { Social motives }\end{array}$} \\
\hline 15 & $\begin{array}{l}\text { Стремление к социальному престижу } \\
\text { Motivation towards social prestige }\end{array}$ & 1,78 & $p<0,05$ \\
\hline 16 & $\begin{array}{l}\text { Стремление к соперничеству } \\
\text { Motivation towards competition }\end{array}$ & 1,92 & $p<0,05$ \\
\hline 17 & $\begin{array}{l}\text { Стремление к достижению цели } \\
\text { Motivation towards goal achievement }\end{array}$ & 1,13 & \\
\hline \multicolumn{4}{|c|}{$\begin{array}{l}\text { Мотивация aфори^иации } \\
\text { Motivation of affiliation }\end{array}$} \\
\hline 18 & $\begin{array}{l}\text { Стремление к ^юАям } \\
\text { Orientation towards people }\end{array}$ & 1,68 & $p<0,05$ \\
\hline 19 & $\begin{array}{l}\text { Боязнь быть отвергнутым } \\
\text { Fear of rejection }\end{array}$ & 1,56 & \\
\hline \multicolumn{4}{|c|}{$\begin{array}{l}\text { Основные потребности } \\
\text { Basic needs }\end{array}$} \\
\hline 20 & $\begin{array}{l}\text { Когнитивные потребности } \\
\text { Cognitive needs }\end{array}$ & 2,11 & $p<0,05$ \\
\hline 21 & $\begin{array}{l}\text { Потребности самореализации } \\
\text { Self-realization needs }\end{array}$ & 0,18 & \\
\hline 22 & $\begin{array}{l}\text { Физиологические потребности } \\
\text { Physiological needs }\end{array}$ & 0,16 & \\
\hline 23 & $\begin{array}{l}\text { Потребности в безопасности } \\
\text { Safety needs }\end{array}$ & 1,01 & \\
\hline 24 & $\begin{array}{l}\text { Социальные потребности } \\
\text { Social needs }\end{array}$ & 0,84 & \\
\hline
\end{tabular}




\begin{tabular}{|c|c|c|c|}
\hline № & $\begin{array}{l}\text { Эмпирические тестовые параметры } \\
\text { мотивационной сферы } \\
\text { Empirical values of motivational sphere }\end{array}$ & $\begin{array}{l}\varphi_{\text {эмп. }} \\
\varphi_{\text {emp. }}\end{array}$ & $\begin{array}{l}\text { Значимость } \\
\text { Significance }\end{array}$ \\
\hline & \multicolumn{3}{|c|}{$\begin{array}{c}\text { Терминальные ценности } \\
\text { Ultimate values }\end{array}$} \\
\hline 25 & $\begin{array}{l}\text { Уверенность в себе } \\
\text { Self-confidence }\end{array}$ & 0,17 & \\
\hline 26 & $\begin{array}{l}\text { Счастливая семейная жизнь } \\
\text { Happy family life }\end{array}$ & 1,12 & \\
\hline 27 & $\begin{array}{l}\text { Интересная работа } \\
\text { Interesting work }\end{array}$ & 1,15 & \\
\hline 28 & $\begin{array}{l}\text { 3Аоровье } \\
\text { Health }\end{array}$ & 1,41 & \\
\hline 29 & $\begin{array}{l}\text { Познание } \\
\text { Knowledge }\end{array}$ & 0,88 & \\
\hline \multicolumn{4}{|c|}{$\begin{array}{l}\text { Инструментальные ценности } \\
\text { Instrumental values }\end{array}$} \\
\hline 30 & $\begin{array}{l}\text { Образованность } \\
\text { Education }\end{array}$ & 0,79 & \\
\hline 31 & $\begin{array}{l}\text { ЖизнераАОстность } \\
\text { Vitality }\end{array}$ & 0,27 & \\
\hline 32 & $\begin{array}{l}\text { Честность } \\
\text { Honesty }\end{array}$ & 1,12 & \\
\hline 33 & $\begin{array}{l}\text { Широта взгАяАОВ } \\
\text { Breadth of views }\end{array}$ & 1,18 & \\
\hline 34 & $\begin{array}{l}\text { Терпимость } \\
\text { Tolerance }\end{array}$ & 0,09 & \\
\hline \multicolumn{4}{|c|}{$\begin{array}{c}\text { Показатели удовлетворенности основных потребностей } \\
\text { Valves of basic needs satisfaction }\end{array}$} \\
\hline 35 & $\begin{array}{l}\text { Материальные потребности } \\
\text { Material needs }\end{array}$ & 0,22 & \\
\hline 36 & $\begin{array}{l}\text { Потребности в безопасности } \\
\text { Safety needs }\end{array}$ & 1,31 & \\
\hline
\end{tabular}




\begin{tabular}{|c|c|c|c|}
\hline № & $\begin{array}{l}\text { Эмпирические тестовые параметры } \\
\text { мотивационной сферы } \\
\text { Empirical values of motivational sphere }\end{array}$ & $\begin{array}{l}\varphi_{\text {эмп. }} \\
\varphi_{\text {emp. }}\end{array}$ & $\begin{array}{l}\text { Значимость } \\
\text { Significance }\end{array}$ \\
\hline 37 & $\begin{array}{l}\text { Потребности в самовыражении } \\
\text { Self-expression needs }\end{array}$ & 1,86 & $p<0,05$ \\
\hline 38 & $\begin{array}{l}\text { Потребности в признании } \\
\text { Recognition needs }\end{array}$ & 1,61 & \\
\hline 39 & $\begin{array}{l}\text { Социальные (межличностные) } \\
\text { потребности } \\
\text { Social (interpersonal) needs }\end{array}$ & 1,15 & \\
\hline 40 & $\begin{array}{l}\text { Показатель обобщенной напряженности } \\
\text { Values of generalized tension }\end{array}$ & 2,22 & $p<0,05$ \\
\hline
\end{tabular}

Примечание: * $\varphi_{\text {крит }}=1,64(p<0,05)$ и $\varphi_{\text {крuт. }}=2,31(p<0,01)$. Note: ${ }^{*} \varphi_{\text {crit. }}=1.64(p<0.05), \varphi_{\text {crit. }}=2.31(p<0.01)$.

\section{Обсуждение результатов}

Таким образом, в результате исследования можно отметить, что для психологов характерны: большая направленность на социальную полезность, преобладание когнитивных потребностей; более важной является инструментальная ценность «образованность», а также показатель психической напряженности, соответствующий удовлетворительному психическому состоянию. Для психиатров более характерна направленность на жизнеобеспечение, социальный статус; социальные потребности проявляются в меньшей степени, при этом показатель психической напряженности соответствует повышенной дискомфортности. Кроме того, для психиатров характерна неудовлетворенность в профессиональной самореализации. Учитывая данные отличия, можно предположить, что выявленные особенности ценностно-мотивационной сферы могут способствовать, в совокупности с рядом других факторов (специфика профессиональной деятельности, высокая степень ответственности и т. д.), более высокому риску возникновения синдрома профессионального выгорания у психиатров.

Проведенное исследование позволило полнее изучить мотивацию и ценностные ориентации психологов и психиатров, что было необходимо для определения потребностей работников, важных для прогноза успешности их профессиональной деятельности. 


\section{Литература}

1. Эннс Е. А. Технологии формирования профессионального самосознания студентов помогающих профессий // Психология в России и за рубежом: материалы Междунар. науч. конф. (г. Санкт-Петербург, октябрь 2011 г.). СПб.: Реноме, 2011. С. 123-125. https://moluch.ru/conf/psy/ archive/32/1128/ (дата обращения: 04.01.2018).

2. Милакова В.В. Психологические особенности профессионального самоопределения будущих специалистов помогающих профессий социономического типа: дисс. ... канд. психол. наук. Астрахань, 2007. 234 с.

3. Сорокоумова С. Н., Исаев В. П. Специфика профессиональной деятельности специалистов помогающих профессий // Педагогическое образование в России. 2013. № 4. С. 186-190.

4. Урываев В. А. Оценка уровня профессиональной психолого-педагогической подготовленности выпускников медицинских вузов руководителями лечебно-профилактических учреждений // Ярославский психологический вестник. 2004. Вып. 11. С. 45-47.

5. Quail M., Brundage S. B., Spitalnick J., Allen P. J., Beilby J. Student self-reported communication skills, knowledge and confidence across standardised patient, virtual and traditional clinical learning environments //BMC Medical Education. 2016. 16:73. DOI: 10.1186/s12909-016-0577-5

6. Phillips S. P., Dalgarno N. Professionalism, professionalization, expertise and compassion: a qualitative study of medical residents // BMC Medical Education. 2017. 17:21. DOI: 10.1186/s12909-017-0864-9

7. Williams B., Brown T., Boyle M., McKenna L., Palermo C., Etherington J. Levels of empathy in undergraduate emergency health, nursing, and midwifery students: a longitudinal study // Advances in Medical Education and Practice. 2014. № 5. P. 299-306. DOI: $10.2147 /$ AMEP.S66681

8. Дьяченко М. И. Психологические проблемы готовности к деятельности / М. И. Дьяченко, Л. А. Кандыбович. Минск: Изд-во БГУ, 1976. 175 с.

9. Жукова В. Ф. Психолого-педагогический анализ категории «психологическая готовность» // Известия Томского политехнического университета. 2012. Т. 320, № 6. С. 117-121.

10. Кучерявенко И. А. Проблема психологической готовности к профессиональной деятельности // Молодой ученый. 2011. Т. 2, № 12. С. 60-62.

11. Шадриков В.Д. Проблемы системогенеза профессиональной деятельности. М.: Наука, 1982. 185 с.

12. Кораблина Е. П., Стоянова Е. Ю., Грибанова О. Н. Психологическая готовность к профессиональной деятельности у студентов медицинского колледжа дневного и вечернего отделений // Научное мнение. 2016. № 15. С. $84-87$. 
13. Емельяненко Л. М. Формирование у студентов-медиков мотивационной готовности к профессиональной деятельности // Научно-исследовательская работа. 2011. № 2. С. 35-38.

14. Фитьмова А. А. Развитие профессиональной мотивации будущих врачей в процессе обучения в вузе: дисс. ... канд. психол. наук. Ставрополь, 2012. 253 c.

15. Зайцева В. М. Индивидуально-психологические особенности личности студентов и мотивы в выборе врачебной специальности: на материале медицинского вуза: дисс. ... канд. психол. наук. Смоленск, 2004. 199 с.

16. Budhathoki S. S., Zwanikken P. A. C., Pokharel P. K., Scherpbier A. J. Factors influencing medical students' motivation to practice in rural areas in lowincome and middle-income countries: a systematic review // BMJ Open. 2017. Vol. 7, Issue 2. DOI: 10.1136/bmjopen-2016-013501

17. Heiligers P. J. M. Gender differences in medical students' motives and career choice // BMC Medical Education. 2012. 12:82. DOI: 10.1186/1472-6920-12-82

18. Kusurkar R. A., Croiset G., Galindo-Garré F., Olle Ten Cate Motivational profiles of medical students: Association with study effort, academic performance and exhaustion // BMC Medical Education. 2013. 13:87. DOI: 10.1186/14726920-13-87

19. Арасланова А. Т. Формирование коммуникативной компетентности студентов в условиях медицинского колледжа: дисс. ... канд. пед. наук. Оренбург, 2008. 237 с.

20. Комолкина О. И., Чернецкая Н. И. Профессиональные ценностные ориентации студентов и особенности их становления в процессе обучения в медицинском колледже // Российский психологический журнал. 2017. T. 14, № 2. C. 105-117. DOI: 10.21702/rpj.2017.2.6

21. Чернецкая Н.И., Комолкина О.И. Мотивы выбора профессии медицинской сестры // Педагогический имидж. 2017. № 4 (37). С. 142-148.

22. Нугаева А. Н. Мотивационно-ценностная сфера личности специалиста-психолога как основа его профессионального развития // Известия Российского государственного педагогического университета им. А. И. Герцена. 2008. № 74-2. С. 203-208.

23. Быков С. В., Ляпина И. А. Эмоциональное выгорание как фактор трудового стресса работников психоневрологического диспансера // Вестник Самарской гуманитарной академии. Серия: Психология. 2013. № 1. С. 85-93.

24. Туран Н. К. О взаимосвязи эмоционального выгорания и профессиональной мотивации врачей общего профиля // Психология в России и за рубежом: материалы II Междунар. науч. конф. (г. Санкт-Петербург, ноябрь 2013 г.). СПб.: Реноме, 2013. С. 104-108. URL https://moluch.ru/ conf/psy/archive/109/4305/ (дата обращения: 16.05.2018). 


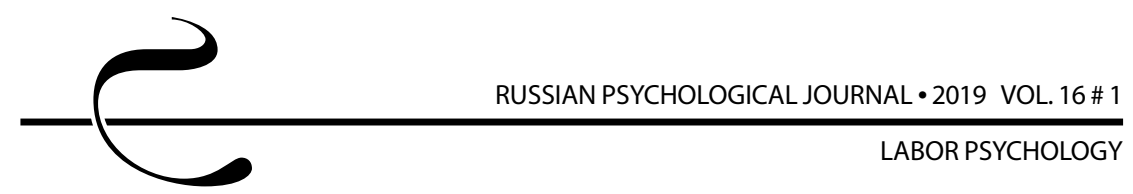

25. Глущенко М. В., Кудрявая Н. В. Место психологии в профессиональной подготовке врача: гуманитарное приложение или составляющая профессиональной идентичности // Ярославский психологический вестник. 2004. Вып. 11. С. 86-87.

26. Дронова Е. А., Еремина М. В. Оценка формирования готовности врача к профессиональной деятельности в экстремальных ситуациях //Успехи современного естествознания. 2011. № 8. С. 101-101.

27. Кузеванова А. Л. Семейный врач в современной России: опыт социального портрета: дисс. ... канд. социол наук. Волгоград, 2004. 180 с.

28. Утробина В. Г. Психологическая подготовка студентов-медиков - необходимое условие профессионализма будущего врача // Ярославский психологический вестник. 2004. Вып. 11. С. 75-76.

29. Виноградова Н. И., Цыдыпова С. Д. Становление профессионального здоровья будущего психолога образования // Ученые записки ЗабГУ. 2013. № 5 (52). С. 111-117.

30. Чернецкая Н. И. Особенности ценностно-смысловых ориентаций личности у представителей профессий системы «человек - человек» // Известия Иркутского государственного университета. Серия: Математика. 2016. Т. 16. С. 57-66.

31. Eisenberg $L$. Is psychiatry more mindful or brainier than it was a decade ago? // The British Journal of Psychiatry. 2000. Vol. 176. P. 1-5.

32. Ильин Е. П. Мотивация и мотивы. СПб.: Питер, 2004. 509 с.

33. Прохоров А. О. Практикум по психологии состояний: Учебное пособие. СПб: Речь, 2004. 480 c.

34. Верещагина Л. А. Психология персонала. Потребности, мотивация и ценности. Харьков: Гуманитарный Центр, 2012. 212 с.

\section{References}

1. Enns E. A. Tekhnologii formirovaniya professional'nogo samosoznaniya studentov pomogayushchikh professii [Technologies of the formation of professional self-consciousness in students of helping professions]. Psikhologiya $v$ Rossii iza rubezhom: materialy Mezhdunar. nauch. konf. [Psychology in Russia and abroad: Proc. the International Theoretical Conference]. St. Petersburg, Renome Publ., 2011, pp. 123-125. Available at: https://moluch. ru/conf/psy/archive/32/1128/ (Accessed 04 January 2018).

2. Milakova V. V. Psikhologicheskie osobennosti professional'nogo samoopredeleniya budushchikh spetsialistov pomogayushchikh professii sotsionomicheskogo tipa [Psychological features of professional self-determination of future specialists of helping professions of a socionomic type]. Diss. Cand. Sci. (Psych.). Astrakhan, 2007. 234 p. 
3. Sorokoumova S. N., Isaev V. P. Specific character of professional activity of specialists of helping professions. Pedagogicheskoe obrazovanie $v$ Rossii - Pedagogical Education in Russia, 2013, no. 4, pp. 186-190 (in Russian).

4. Uryvaev V. A. Assessing the level of professional psychological and pedagogical readiness of graduates of medical schools heads of medical institutions. Yaroslavskii psikhologicheskii vestnik - Yaroslavl Psychological Bulletin, 2004, V. 11, pp. 45-47 (in Russian).

5. Quail M., Brundage S. B., Spitalnick J., Allen P. J., Beilby J. Student self-reported communication skills, knowledge and confidence across standardised patient, virtual and traditional clinical learning environments. BMCMedical Education, 2016, 16:73. DOI: 10.1186/s12909-016-0577-5

6. Phillips S. P., Dalgarno N. Professionalism, professionalization, expertise and compassion: a qualitative study of medical residents. BMC Medical Education, 2017, 17:21. DOI: 10.1186/s12909-017-0864-9

7. Williams B., Brown T., Boyle M., McKenna L., Palermo C., Etherington J. Levels of empathy in undergraduate emergency health, nursing, and midwifery students: a longitudinal study. Advances in Medical Education and Practice, 2014, no. 5, pp. 299-306. DOI: 10.2147/AMEP.S66681

8. D'yachenko M. I. Psikhologicheskie problemy gotovnosti k deyatel'nosti [Psychological problems of readiness for activity]. Minsk, BSU Publ., 1976. 175 p.

9. Zhukova V. F. Psychological and pedagogical analysis of the category of 'psychological readiness'. Izvestiya Tomskogo politekhnicheskogo universiteta - Proceedings of Tomsk Polytechnic University, 2012, V. 320, no. 6, pp. 117-121 (in Russian).

10. Kucheryavenko I. A. Problem of psychological readiness for professional activity. Molodoi uchenyi - Young Scientist, 2011, V. 2, no. 12, pp. 60-62 (in Russian).

11. Shadrikov V. D. Problemy sistemogeneza professional'noi deyatel'nosti [Problems of the system genesis of professional activity]. Moscow, Nauka Publ., 1982. $185 \mathrm{p}$.

12. Korablina E. P., Stoyanova E. Yu., Gribanova O. N. Psychological readiness for professional activity in day and evening students of a medical college. Nauchnoe mnenie - Scientific Opinion, 2016, no. 15, pp. 84-87 (in Russian).

13. Emelyanenko L. M. Formation of motivational readiness for professional activity among medical students. Nauchno-issledovatel'skaya rabota - Research Work, 2011, no. 2, pp. 35-38 (in Russian).

14. Fit'mova A. A. Razvitie professional'noi motivatsii budushchikh vrachei $v$ protsesse obucheniya $v$ vuze [Development of professional motivation in future physicians during training in higher school]. Diss. Cand. Sci. (Psych.). Stavropol, 2012. 253 p. 
15. Zaitseva V. M. Individual'no-psikhologicheskie osobennosti lichnosti studentov i motivy $v$ vybore vrachebnoi spetsial'nosti: na materiale meditsinskogo vuza [Individual and psychological characteristics of students' personality and motives for choosing a medical specialty: A case of medical high schools]. Diss. Cand. Sci. (Psych.). Smolensk, 2004. 199 p.

16. Budhathoki S. S., Zwanikken P. A. C., Pokharel P. K., Scherpbier A. J. Factors influencing medical students' motivation to practice in rural areas in lowincome and middle-income countries: a systematic review. BMJ Open, 2017, V. 7, Issue 2. DOI: 10.1136/bmjopen-2016-013501

17. Heiligers P. J. M. Gender differences in medical students' motives and career choice. BMCMedical Education, 2012, 12:82. DOI: 10.1186/1472-6920-12-82

18. Kusurkar R. A., Croiset G., Galindo-Garré F., Olle Ten Cate. Motivational profiles of medical students: Association with study effort, academic performance and exhaustion. BMCMedical Education, 2013, 13:87. DOI:10.1186/1472-6920-13-87

19. Araslanova A. T. Formirovanie kommunikativnoi kompetentnosti studentov $v$ usloviyakh meditsinskogo kolledzha [Formation of communicative competence among students in the medical college]. Diss. Cand. Sci. (Ped.). Orenburg, 2008. $237 \mathrm{p}$.

20. Komolkina O. I., Chernetskaya N. I. Students' professional value guidelines and their formation when studying at a medical college. Rossiiskii psikhologicheskii zhurnal - Russian Psychological Journal, 2017, V. 14, no. 2, pp. 105-117 (in Russian). DOI: 10.21702/rpj.2017.2.6

21. Chernetskaya N. I., Komolkina O. I. The motives for choosing nursing as a profession. Pedagogicheskii imidzh - Pedagogical Image, 2017, no. 4 (37), pp. 142-148 (in Russian).

22. Nugaeva A. N. Motive-value sphere of a psychologist's personality as a basis of his/her vocational development. Izvestiya Rossiiskogo gosudarstvennogo pedagogicheskogo universiteta im. A. I. Gertsena - Proceedings of Herzen Russian State Pedagogical University, 2008, no. 74-2, pp. 203-208 (in Russian).

23. Bykov S. V., Lyapina I. A. Emotional burnout as a factor of working stress in employees of psychoneurological dispensaries. Vestnik Samarskoi gumanitarnoi akademii. Seriya: Psikhologiya - Bulletin of the Samara Humanitarian Academy. Series: Psychology, 2013, no. 1, pp. 85-93 (in Russian).

24. Turan N. K. O vzaimosvyazi emotsional'nogo vygoraniya i professional'noi motivatsii vrachei obshchego profilya [On the relationship of burnout and professional motivation in general practitioners]. Psikhologiya $v$ Rossii i za rubezhom: materialy Mezhdunar. nauch. konf. [Psychology in Russia and abroad: Proc. the International Theoretical Conference]. St. Petersburg, Renome Publ., 2011, pp. 104-108. Available at: https://moluch.ru/conf/ psy/archive/109/4305/ (Accessed 16 May 2018). 
25. Glushchenko M. V., Kudryavaya N. V. The role of psychology in the professional training of physicians: Humanities application or a component of professional identity. Yaroslavskii psikhologicheskii vestnik - Yaroslavl Psychological Bulletin, 2004, V. 11, pp. 86-87 (in Russian).

26. Dronova E. A., Eremina M. V. Assessing the formation of a physician's readiness for professional activity in extreme situations. Uspekhi sovremennogo estestvoznaniya - Advances in Modern Natural Science, 2011, no. 8, pp. 101-101 (in Russian).

27. Kuzevanova A. L. Semeinyi vrach v sovremennoi Rossii: opyt sotsial'nogo portreta [The family doctor in modern Russia: An experience of a social portrait]. Diss. Cand. Sci. (Soc.). Volgograd, 2004. 180 p.

28. Utrobina V. G. Psychological training of medical students as an important condition for the professionalism of future doctors. Yaroslavskii psikhologicheskii vestnik - Yaroslavl Psychological Bulletin, 2004, Issue 11, pp. 75-76 (in Russian).

29. Vinogradova N. I., Tsydypova S. D. Formation of the professional health of future education psychologists. Uchenye zapiski ZabGU - Scholarly Notes of Transbaikal State University, 2013, no. 5 (52), pp. 111-117 (in Russian).

30. Chernetskaya N. I. Characteristics of personal value meaning orientations in representatives of 'subject - subject' professions. Izvestiya Irkutskogo gosudarstvennogo universiteta. Seriya: Matematika - Izvestiya of the Irkutsk State University. Series: Mathematics, 2016, V. 16, pp. 57-66 (in Russian).

31. Eisenberg L. Is psychiatry more mindful or brainier than it was a decade ago? The British Journal of Psychiatry, 2000, V. 176, pp. 1-5.

32. Il'in E. P. Motivatsiya i motivy [Motivation and motives]. St. Petersburg, Piter Publ., 2004. 509 p.

33. Prokhorov A. O. Praktikum po psikhologii sostoyanii [Tutorial of the psychology of states]. St. Petersburg, Rech' Publ., 2004. 480 p.

34. Vereshchagina L. A. Psikhologiya personala. Potrebnosti, motivatsiya i tsennosti [Psychology of personnel: Needs, motivation, and values]. Kharkov, Gumanitarnyi Tsentr Publ., 2012. 212 p. 